\title{
NOTAS SOBRE OS FUNDAMENTOS DA EDUCAÇÃO SOB MÚLTIPLAS VISÕES
}

LIMA, P. G.; MARQUES, S. C. M. (Org.). Fundamentos da educação: recortes e discussões. 1. ed. Jundiaí: Paco Editorial, 2015. v. 2.

Meira Chaves Pereira*

Docente da Rede Oficial de Ensino do Estado de São Paulo

A evolução do pensamento pedagógico a partir das comunidades primitivas até o surgimento das universidades é a temática central da obra, que teve o início de sua série com o Volume 1, e que agora, considerando o itinerário cronológico, estende-se até o fim da Idade Média e desdobra uma visão de conjunto sobre os principais representantes do pensamento educacional.

O livro, lançado pela Paco Editorial da Cidade de Jundiaí, SP, é uma organização de textos selecionados pelos Professores Paulo Gomes Lima, Doutor em Educação Escolar pela Universidade Estadual Paulista de Araraquara, SP, e Professor do Programa de Pós-Graduação em Educação da Universidade Federal de São Carlos, Campus de Sorocaba, SP, e Silvio Cesar Moral Marques, Doutor em Filosofia pela USP e Docente do PPGED da UFSCAR, Campus de Sorocaba. Reúne, portanto, as contribuições de pesquisadores de universidades públicas e privadas do Brasil, além de contribuições de acadêmicos dos cursos de pós-graduação stricto sensu. Ao todo são 22 capítulos reunidos em 364 páginas.

As socializações das temáticas em cada um dos capítulos trazem elementos atuais e recorrentes para o estudo e reflexão sobre o pensamento pedagógico na História. Digna de destaque é a preocupação didática com o leitor, na explicitação de uma linguagem bem trabalhada e acessível tanto para o estudante iniciante quanto para o pesquisador mais experiente.

A temática que dá abertura ao livro, escrita pelo Professor Elicio Gomes Lima, apresenta uma análise da educação primitiva como um processo de adaptação da vida ao meio natural e aos grupos sociais a que os indivíduos pertenciam, nas eras

\footnotetext{
*Mestranda em Educação pela Universidade Federal de São Carlos, Campus de Sorocaba; meira.chaves@ gmail.com
} 
da Pré-História humana, desde o surgimento dos primeiros Hominídeos, do Homo sapiens, até o aparecimento da escrita, em torno de 4.000 a.C., e o início das primeiras civilizações humanas, nas quais já aparece uma preocupação implícita e explícita de uma educação intencional para a transmissão de conhecimentos e para a formação das novas gerações.

A Educação Chinesa é a temática seguinte, tratada pelo Professor Gabriel Lomba Santiago. Destaca o autor que a China é marcante por sua presença cultural original, como também um antes e depois de Confúcio, do Império à República e desta ao socialismo. A moral, a família, o meio ambiente e a cosmologia interagiam para moldar o homem virtuoso, responsável e criativo a caminho da sabedoria. Da linguagem e escrita, busca do saber e ciência sintetizam teoria e prática. Hoje recolhem os frutos desse caminho às vezes utópico e científico, mas sem perder jamais de vista a educação.

A terceira temática, da Professora Rute de Carvalho Angelini, tem como tema $A$ Educação Hindu. O capítulo destaca que a Índia faz parte das grandes civilizações antigas da humanidade que, com seu misticismo, suas crenças, seus deuses e seus rios considerados sagrados revela uma significativa riqueza histórica de conhecimentos culturais, sociais e educacionais. Esse capítulo vem compartilhar os traços da civilização indiana, o que inclui também o sistema político e, principalmente, o religioso, que dá sustentação ao processo educativo. Falar sobre a Índia se torna um desafio, visto que suas tradições e contradições sociais muito se diferenciam da sociedade ocidental. É uma descoberta além das expectativas.

Vânia Lúcia Ruas Chelotti de Moraes desdobra a temática sobre $A$ Educação Egípcia. A autora observa que a história do ensino no Egito está intimamente relacionada com a religião e com a cultura e nitidamente articulada segundo o modelo de classe e de governo, pressupondo a ênfase no tradicionalismo com objetivos de transmitir às novas gerações o patrimônio cultural do seu povo (religião, ciência, arte, língua). No texto, as peculiaridades do processo educacional dessa civilização são destacadas considerando relação, forma, conteúdo e finalidade da tipologia de educação, onde o para quem e em que condições se centraram em que o principal foco.

Escrito por Rubens Rodrigues Lima, A Educação Hebraica, é a temática que segue o livro. Segundo o autor do capítulo, para a nação hebraica, a influência ou significação política na educação das crianças e jovens não era conduzida pela mesma lógica dos demais povos, o seu foco era diferenciado, sobretudo, pelo profundo 
conteúdo moral de sua religiosidade. Tudo precisava fazer sentido na educação de uma criança, desde a escolha do nome, que certamente deveria conter algum significado relacionado à índole do indivíduo - na leitura dos pais ou sacerdotes - ou em homenagem a algum parente que teve uma marcante liderança ou história de vida. $\mathrm{O}$ teocratismo como condutor da vida social e política do povo hebreu é uma das características tratadas nesse capítulo.

A professora Flávia Leila da Silva, no capítulo $A$ Educação Heroica - $A$ Odisséia e a Ilíada, apresenta algumas reflexões acerca da educação heroica presente nos poemas homéricos: a Ilíada e a Odisseia. Pelo contato com esses poemas, observa a autora, os jovens gregos que pertenciam à aristocracia eram inspirados pela busca das virtudes que possuíam seus personagens, como a honra, a coragem e a amizade. Considera-se, por meio desse estudo, o papel educativo desses poemas, pois eram instrumentos utilizados na elaboração de uma educação que visava à formação de um modelo educacional que iria, ao longo do tempo, influenciar de forma considerável as concepções educacionais ocidentais.

Izabel de Carvalho Gonçalves Dias trata da Educação Cívica em Esparta e Atenas. Duas cidades gregas que se rivalizavam e que mais se destacaram na Grécia Antiga. Esparta, uma sociedade de regime autoritário militarizado com uma educação de caráter totalitário e civismo repressivo, com os interesses voltados para o Estado; Atenas, uma sociedade aberta, democrática para o padrão daquela época e que priorizava a formação integral do homem, a partir de uma tipologia educacional como meio para o indivíduo alcançar o conhecimento da verdade, da justiça, do belo e da virtude, para a prática ideal da cidadania plena.

Carolina Aparecida Rosa escreve sobre O pensamento pedagógico de Sócrates; apresenta, inicialmente, uma breve biografia do filósofo ateniense e, na sequência, dirige-se à discussão de seu método de ensino de base filosófica centrado na ironia e maiêutica, bem como o conceito de paideia diferenciado. A autora apresenta reflexões acerca do posicionamento crítico e instigador sustentado por Sócrates aplicado à realidade e prática filosófica e à política do educador contemporâneo, considerando a necessidade de autoanálise e autoconhecimento para formulação de questionamentos diante das orientações de sistemas educacionais meramente reprodutivistas. Objetiva-se, portanto, pensar como o emprego do método socrático pode colaborar na construção de uma forma crítica e relacioná-lo ao ensino escolar. 
Kleyton Carlos Ferreira é o escritor da temática nove, $O$ pensamento pedagógico de Platão. O autor destaca que, para Platão, seria tarefa da sociedade aprender a valorizar preceitos educativos da ética, da moral e da justiça social, para que fossem constituídos como sujeitos do bem (cidadãos morais). Para isso, o campo da filosofia política não deveria estar distanciado da pedagogia e da arte, entre outras áreas do conhecimento. A educação em Platão deveria ser acompanhada de um projeto político, o que evitaria a uniformização dos cidadãos, auxiliando-os a se perceberem como tais, de acordo com as habilidades de cada um, tendo como fim a produção de bens para todos, assim, tudo o que seria produzido deveria ser compartilhado de maneira justa.

A temática 10 foi escrita pela professora Telma Elizabete de Moraes, $O$ pensamento pedagógico de Isócrates, que na história da educação se destaca como fundador de uma das escolas em Atenas, em torno do ano 390 a.C. O sistema retórico de grande estilo e verdadeiramente político levou Isócrates a ser reconhecido como grande influenciador da história específica de Atenas e como um dos mais destacados representantes da retórica grega.

O capítulo 11, de Paulo Gomes Lima, trata de $O$ pensamento pedagógico de Aristóteles. Destaca o autor que, em sua obra A Politica, Aristóteles trabalha sobre a doutrina do Estado desde a sua concepção propriamente dita, assim como as formas que podem caracterizá-lo, e, nessa perspectiva, discorre sobre os principais direitos e deveres que o "cidadão" deve exercer a fim de que o "todo" (Estado) possa ajudar as "partes" (cidadãos e instituições) e vice-versa. O capítulo está organizado em três partes complementares, a saber: Biografia de Aristóteles, características e obras; Compreendendo a eugenia e a educação aristotélica; e, O processo educativo.

Cristiane de Sá Dan escreve sobre $O$ pensamento pedagógico helenístico. É apresentada a contextualização do pensamento pedagógico helenístico e suas concepções educacionais em três eixos: o período helenístico, a cultura helenística e o pensamento pedagógico helenístico. Pretende a autora dar a conhecer ao leitor como ocorreu esse período, sua cultura e seu modelo educacional.

Meira Chaves Pereira escreveu sobre A Educação Romana no capítulo 13. Para efeitos desse capítulo, a autora destaca as principais manifestações da educação romana, a partir de três períodos destacados por Luzuriaga (1987): a educação na época heroico-patrícia (século V ao III a.C.); a educação romana sob a influência grega (séc. III ao I a.C.) e a Educação romana na época do Império (séc. I ao V da era cristã). Interessante é a ênfase dada ao âmbito formal, característico do povo romano. 
Noêmia de Carvalho Garrido discute $O$ pensamento pedagógico de Santo Agostinho. Na discussão em tela, a partir de alguns recortes da obra de Agostinho De Magistro, a autora analisa o processo educativo da época, tendo como pano de fundo o papel da igreja, o cristianismo e a busca de respostas para as manifestações do mundo no dogmatismo relacionado à origem divina, a escolástica e, por fim, uma reflexão em torno do diálogo entre Santo Agostinho e seu filho Adeodato.

A professora Silmara Aparecida Lopes, no capítulo XV, trata do Pensamento pedagógico na ordem dos beneditinos (São Bento de Núrsia). Nesse capítulo, a autora discute o papel desempenhado pelo monasticismo ocidental, mormente da Ordem Beneditina, tendo como fio condutor a educação cristã na primeira fase da Idade Média. Bento fora um monge italiano que nascera por volta de 480 d.C., na região de Núrsia. São Bento de Núrsia (480-547) viveu na transição da Antiguidade para a Idade Média, período marcado pela decadência do Império Romano e pelo desmantelamento das instituições romanas; assim, como as escolas oficiais e particulares foram desaparecendo, a Igreja iniciou o desenvolvimento das escolas paroquiais e episcopais para a formação do clero, e as escolas monásticas constituíram-se uma das principais instituições educativas dessa fase, tornando-se espaço especial de preservação da vida, da cultura e da escrita no Ocidente medievo.

Mariclei Przylepa trata sobre $O$ pensamento pedagógico na Ordem dos Dominicanos. O capítulo destaca as principais contribuições dessa ordem religiosa ao campo pedagógico. Para tanto, o estudo inicia abordando o contexto social do século XIII, apresenta a Ordem dos Dominicanos e, na sequência, evidencia as suas formas de estudo e a concepção de ensino e finaliza com destaques dessa Ordem no processo de instrução na Baixa Idade Média.

Ester Chichaveke trata do pensamento pedagógico na Ordem dos Franciscanos durante a Idade Média Ocidental. Os mendicantes, como foram chamados, assumiram o carisma e o legado deixados por Francisco de Assis e exerceram papel de destaque quanto à evangelização e à cristianização da Europa, aliada à prática educativa e pedagógica. Para isso, utilizaram como procedimento didático a junção complementar e harmônica entre fé e racionalidade, dons gratuitos oferecidos aos homens. Enfatiza a autoria que em terras brasileiras e em era colonial, os Franciscanos foram os pioneiros na missão e na instrução, de forma que ensinaram as primeiras letras aos nativos, aos descendentes de colonos e aos negros. 
A temática 18, desenvolvida por Paulo Gomes Lima e Lilian Tatiane Candia de Oliveira, trata do pensamento pedagógico de Santo Tomás de Aquino. No processo de educação do ser humano, ele considera que Deus introduz em cada homem os princípios fundamentais de todos os conhecimentos, mas todas as deduções e aplicações destes são feitos dos homens e suas experiências. Assim, a educação por meio do auxílio do professor ajudará o aluno a transformar sua potência intelectual em ato, como em um processo de atualização do conhecimento. Esse processo de construção, segundo Tomás, de forma nenhuma coloca Deus em segundo plano, muito pelo contrário, situa-o como protagonista da história do homem, e exatamente por isso a educação é considerada por ele como autoeducação, uma vez que estimula o contato com a realidade divina elaborada em favor do homem.

Silvio Cesar Moral Marques desenvolve, no capítulo 19, Os elementos da educação moral religiosa medieval: os bestiários. $\mathrm{O}$ autor observa que a utilização de animais para expressar sentimentos, condutas e características humanas tem uma longa tradição em diferentes sociedades. Dessa maneira, o emprego como elemento metafórico das ações humanas apresenta longa tradição; entretanto, a principal característica no seu uso por parte do cristianismo foi em alegorias religiosas. Um bestiário, ou "livro das bestas", vai além da Fisiologia ou da História Natural, bem como das lendas e tradições dos povos que a influenciaram: seu objetivo é a descrição e o ensino de um mundo como ele era concebido naquele momento.

O capítulo 20, escrito pela professora Sonia Maria Borges de Oliveira, trata da formação do pensamento pedagógico cristão no período da Alta Idade Média, com o objetivo de contribuir para a compreensão de suas influências decorrente da forma de instrução para a educação ocidental. O texto faz, no primeiro momento, uma breve contextualização histórica sobre a formação da Alta Idade Média, depois discorre sobre a organização da educação no referido período e, na sequência, sintetiza o pensamento pedagógico caracterizado pela cultura da primeira metade do medievo. De modo geral, observa a autora, a educação na Alta Idade Média tinha a visão teocêntrica como fundamento para a ação pedagógica e buscava, por meio da aplicação desse fundamento, conduzir o povo ao alcance da plenitude da vida moral e espiritual.

Alessandra Cristina Furtado e Adriana Aparecida Pinto desenvolveram a temática sobre $A$ educação na baixa idade média, no capítulo 21. O tema tratado neste capítulo tem como periodização os séculos XII a XV. No que se refere aos aspectos educacionais, é nesse período que as escolas episcopais e as universidades foram con- 
solidadas e sua forma de organização estrutural e didática foi amplamente utilizada, contribuindo para a organização de um modelo de educação que serviria de base para, nos séculos seguintes, originar a criação das escolas laicas e regulares, como conhecemos no século XX. Diante disso, as autoras focalizam, sobretudo, o surgimento e a consolidação das universidades no período e a sua importância na Baixa Idade Média, cuja herança pode ser observada nas instituições de ensino superior surgidas ao redor do mundo inteiro.

O professor Edson Segamarchi dos Santos desdobrou no último capítulo (22) a temática sobre $O$ surgimento da universidade e a escolástica como meio pedagógico, tecendo algumas considerações acerca do método escolástico, criado no interior da Igreja Católica durante a Idade Média, e que remete à ideia de escola que vai se desenvolver em períodos posteriores. Faz-se necessário ressaltar que a Escolástica expressou, em boa medida, o pensamento e o modo de ser do homem medieval. O autor também trata da relação existente entre a Escolástica e o surgimento das primeiras universidades na Europa nesse período, além disso, contempla no texto algumas pontuações sobre as transformações econômicas, políticas e sociais ocorridas no fim do medievo e que impactaram decisivamente os inúmeros campos de atividade humana, incluindo a educação.

Diante do escopo do livro apresentado, observa-se a sua preocupação em contextualizar todo o período cronológico dos fundamentos da educação, o que contribui de forma significativa para o âmbito da descoberta e da crítica na área, portanto, a obra é recomendável e apropriada para estudos em aprofundamento e para estudantes que iniciam pesquisas em educação.

A obra traz uma linguagem atual, reflexiva e recorrente; as temáticas, para além da pertinência, colaboram para a compreensão e analogia com a educação contemporânea, o que nos remete a defendê-la como uma das leituras de referência para cursos de licenciatura em geral.

Recebido em 07 de março de 2015

Aceito em 01 de dezembro de 2015

Endereço para correspondência: Rodovia Washington Luís, Km 235, s/n, Jardim Guanabara, 13565-905, São Carlos, São Paulo, Brasil; meira.chaves@gmail.com 
